Article

\title{
The Empirical Ties between Religious Motivation and Altruism in Foster Parents: Implications for Faith-Based Initiatives in Foster Care and Adoption
}

\author{
Michael Howell-Moroney \\ Division of Public and Nonprofit Administration, University of Memphis, 134 McCord Hall, \\ Memphis, TN 35244, USA; E-Mail: michael.hm@memphis.edu; Tel.: +1-901-678-2640
}

Received: 9 June 2014; in revised form: 31 July 2014 / Accepted: 31 July 2014 /

Published: 8 August 2014

\begin{abstract}
Amidst a crisis shortage of foster homes in the child welfare system, a number of innovative faith-based collaborations aimed at recruiting foster parents have recently emerged. It has been suggested that these collaborations offer a unique opportunity to recruit committed and altruistic parents as caregivers, providing much needed capacity to an overloaded child welfare system. This paper uses data from the National Survey of Current and Former Foster Parents to examine the associations between religious motivations for fostering, altruism and various measures of foster home utilization and longevity. The empirical results demonstrate that religiously motivated foster parents are more likely to have altruistic reasons for fostering, and scored higher than the non-religiously motivated group on an index of altruism. A separate empirical analysis shows that the interaction of high levels of altruism and religious motivation is associated with higher foster home utilization. No association was found between religious altruism and the parent's expressed intent to continue providing foster care. The implications of these findings for current faith-based collaboration in the child welfare arena are discussed.
\end{abstract}

Keywords: altruism; foster care; religion

\section{Introduction}

Occasionally, there are reasons why the State must step in to remove children from their biological parents or other caregivers. Reasons for bringing children into the foster care system 
range from abuse and neglect to cases where one or both parents is temporarily incapacitated by injury, or even the death of the parents. According to the most recently released data from the U.S. Department of Health and Human Services [1] there were about 398,000 children and youth in foster care in 2012. Moreover, $47 \%$ of all children in foster care reside in family foster homes, with another $28 \%$ residing in relative family foster homes, making relative and family foster homes the frontline providers of the foster care system [1]. In fact, family foster homes used to comprise a larger percentage of placements, but it has become increasingly difficult to recruit new families to serve as caregivers and to retain the families that are recruited [2-5].

Recruitment and training of foster families is an expensive and time consuming undertaking that puts pressure on already limited federal resources for child welfare [6]. Consequently finding effective means to recruit and retain foster families is a central policy priority for ensuring the future of the child welfare system. Orme and colleagues sum up the urgency of the issue well when they describe foster families as, “... a critical, national resource that is in short supply” ([7], p. 307).

One strategy that has been widely discussed as a best practice for recruiting foster parents is promotion of foster care in local faith-based congregations [8-12]. A report from the Urban Institute found that 32 states had some sort of targeted faith-based recruiting efforts in place to recruit adoptive and/or foster parents [13]. Some state welfare bureaucracies have begun to devote some of their resources toward efforts to partner with individual faith congregations (or consortiums) for the purpose of recruiting families to provide foster care. For example, the Texas Department of Family and Protective Services recently launched a program called Congregations Helping in Love and Dedication (CHILD).

Other collaborations with government have been initiated from the faith community side, where religious bodies or para-church organizations have approached child welfare officials to explore how they can become involved in recruiting and supporting foster families. A prime example of such an endogenous effort on the part of the faith community is Project 1.27 in Colorado, which was begun by a consortium of Christian churches that committed to providing adoptive homes for all of the children in the state foster care system for whom parental rights had been terminated. Project 1.27 has been replicated in Arizona and was the basis for a similar program in Arkansas as well. Other examples include the Dallas-Fort Worth Alliance of Adoption and Orphan Care Ministries in the Dallas Fort Worth area, a network of several faith-based congregations working cooperatively to encourage and support adoption and foster care. In Los Angeles, a similar interfaith consortium exists called Faith Communities for Families and Children [14].

Despite the growth of faith-based collaboration in the child welfare system, there is little evidence-based research to suggest whether they are successful. (In fact, there is very little research at all that deals with faith-based initiatives in child welfare.) This paper seeks to fill this gap by testing some empirical propositions that have implications for faith-based collaboration in the child welfare system.

This paper provides an empirical examination of the associations between religious motivation for fostering, altruism and various measures of foster family utilization and longevity using data from the National Survey of Current and Former Foster Parents (NSCFFP). After laying the groundwork for understanding the potential importance of the intersections between religiosity and altruism in the specific context of foster care, the next section describes the data from the NSCFFP. 
The following section presents empirical results examining the relationship between religious motivation and altruism. The paper then turns to an examination of the empirical relationships among religious motivation, altruism and substantive foster home outcomes. The paper then concludes with some insights, policy implications and recommendations for continued work.

\section{Religiosity, Altruism and Fostering}

Scholars suggest that the parent's motivation for fostering is crucial because it has an impact on outcomes for foster parents and their foster children. In particular, there seems to be widespread agreement that altruistically-motivated foster parents are among the most desirable [15-21].

But what is it about altruistic motivation that makes it such an attractive trait for foster parents? There are several explanations that we find in the literature. Scholars assert that altruism is a desirable attribute for potential foster parents because it may result in greater commitment to, and hence, longevity in fostering [16,19]. Others propose that parents with altruistic motives are better able to cope with the inevitable difficulties that arise with foster children because their motivation is not solely contingent on circumstances [15].

Motivation theory has been used as a means to explain the importance of altruism. Researchers suggest that intrinsic rewards, such as those that accrue to those who act because they believe they are doing something of value, often will serve to motivate better than extrinsic rewards such as money or personal accolades.

“...parents who are internally motivated to care for children, whether out of a perceived responsibility to the larger society or their knowledge of the harm that could come to the child if they were to continue living with their families, are more likely to stay with the job of fostering."([19], p. 1140).

Other work echoes this idea of intrinsic motivation. A recent study found that foster parents who stuck with foster care were often motivated by the intrinsic rewards of foster care such as making a difference in a child's life or fulfilling an obligation to society [22]. There also is some empirical support linking altruism and to foster parent quality and satisfaction. One study found that parents with altruistic motivation for fostering were more likely to have received higher ratings by their social worker [16]. Other work found that possession of an altruistic motivation for fostering was associated with higher reported levels of foster parent satisfaction [17], though a recent study of foster parents in Belgium found no relationship between foster parent motives and the number of years spent fostering [23]. It is also important to note that though altruism is seen as a desirable trait for foster parents, it is not all-sufficient. Research reminds us that financial and community supports are also important things to provide to foster parents [24].

Clearly, altruism seems to be a desirable attribute for foster parents to possess, but how does altruism relate to religious motivation? Why would local religious congregations, in particular, be places of interest for recruiting foster families? Other scholarly work has found that pre-service motives for fostering, such as religious motivation, are important determinants for the eventual decision to become a foster parent [25]. However, the specific idea of religiosity and its association with altruistic motives for fostering, though supported in an older study in Australia [18], has not 
received much attention since. Given the many faith-based collaborations that are appearing in state child welfare systems across the country, a re-examination of the specific effects of religious beliefs on substantive fostering outcomes is certainly warranted.

\section{Data}

This paper uses high quality survey data from the National Survey of Current and Former Foster Parents. Commissioned in 1990 by the U.S. Department of Health and Human Service, the National Survey of Current and Former Foster Parents (NSCFFP) is the only nationally representative study of current and former foster parents. Before getting into the details of the dataset, it must be acknowledged that these are older data. Scholars have noted that there have been some shifts in the demographic composition of the foster parent population since the 1990s, so that is an explicit limitation in using this database. On the other hand, these are the only nationally representative data of current and former foster parents, so for the purposes of this study, these data are the best we have available for the research questions posed here.

The actual surveying was carried out in 1991 using a complex multi-stage stratified sample design. In the first stage, states were stratified according to high, medium or low foster payment status and sampled according to child population. Nine states were selected at the first stage. Then counties within the states were stratified by unemployment rate and urbanicity and clustered. From this set of counties, sixteen were selected. In order to make this sample nationally representative, posterior weights were calculated and provided with the NCSFFP [26].

Even when the weights are employed to make the sample nationally representative, the multi-stage stratification design creates clustering and other design effects, which are not taken into account with conventional statistical algorithms. Ignoring these design effects in the calculation of standard errors used in a variety of statistical tests will produce erroneous results. In most cases, employing conventional standard errors (based on the simple random sampling assumption) will tend to underestimate the true variance of a given parameter. The NCSFFP provides jackknife replicate weights which are used to produce accurate standard errors.

This paper uses the Current Foster Parent data file for the analysis. The total unweighted sample for the Current Foster Parent data is 1056 cases. However, because the primary subjects of interest for this paper are family-based foster parents, the analysis is limited to currently licensed, family-based and kinship foster homes, so group homes are excluded from the analysis. After eliminating these, the remaining unweighted sample is 901 cases, although, depending upon the particular empirical application, additional cases were unusable due to missing data on one or more relevant variables.

\section{Religious Motivation and Altruism}

This section of the paper addresses the first proposition, that religiously motivated foster parents possess a higher incidence of altruism. The NCSFFP provides a menu of 27 possible reasons for fostering, one of which is "religious beliefs". Respondents were able to mark off any (or all) of the 27 reasons if they were pertinent to their own decision to become foster parents. Therefore, many of 
those that chose religious beliefs as a reason chose other reasons as well. The weighted percentage of respondents that listed religious beliefs as a motivation for fostering is about $13 \%$.

The potential association between religiosity and altruism lends itself to a number of potentially empirically verifiable propositions Do people that foster for religious reasons score more highly on other altruistic motivations for fostering? And, on the flipside, do people that foster for religious reasons also foster for non-altruistic reasons as well? We begin with a straightforward approach, examining the differences in proportions in other reasons for fostering between foster parents who were religiously motivated and those that were not.

As mentioned earlier, the NSCFFP allowed respondents to check off up to 27 different reasons for fostering. Table 1 contains the percentages of respondents that selected each of the other 26 motivations for fostering, stratified by religious motivation. Simple $t$ tests were performed to detect any differences between religiously and non-religiously motivated foster parents.

Table 1. Reasons for Fostering by Religious Motivation.

\begin{tabular}{|c|c|c|c|}
\hline Reason for Fostering & $\begin{array}{l}\text { Not Religiously } \\
\text { Motivated }\end{array}$ & $\begin{array}{l}\text { Religiously } \\
\text { Motivated }\end{array}$ & $t$ Statistic \\
\hline Am related to child & $1.97 \%$ & $4.01 \%$ & 0.99 \\
\hline Child to help with chores/business & $0.10 \%$ & $4.20 \%$ & $1.83 *$ \\
\hline Companion for myself & $12.24 \%$ & $14.55 \%$ & 0.58 \\
\hline Companion for own child & $15.67 \%$ & $13.79 \%$ & -0.44 \\
\hline Couldn't have children & $27.64 \%$ & $31.00 \%$ & 0.42 \\
\hline Didn't want to care for infant & $5.46 \%$ & $10.30 \%$ & 1.54 \\
\hline Foster parenting as a way to adoption & $28.21 \%$ & $34.28 \%$ & 1.11 \\
\hline Give home to child who would've been in institution & $65.52 \%$ & $79.57 \%$ & $3.50 * * *$ \\
\hline Had child who died & $3.88 \%$ & $7.48 \%$ & $1.43^{+}$ \\
\hline Knew the foster child or child's family & $11.32 \%$ & $15.72 \%$ & 1.01 \\
\hline Own children grown, wanted more & $25.28 \%$ & $26.58 \%$ & 0.21 \\
\hline Single \& wanted child & $5.93 \%$ & $6.08 \%$ & 0.06 \\
\hline Thought child would help marriage & $0.52 \%$ & $3.01 \%$ & 1.23 \\
\hline Wanted certain type of child & $11.39 \%$ & $19.37 \%$ & $1.67^{+}$ \\
\hline Wanted larger family & $29.79 \%$ & $37.94 \%$ & 1.01 \\
\hline Wanted to adopt, couldn't get child & $12.44 \%$ & $18.64 \%$ & 1.01 \\
\hline Wanted to be loved by a child & $44.75 \%$ & $35.23 \%$ & $-1.74^{+}$ \\
\hline Wanted to care for child, but didn't want permanent responsibility & $15.14 \%$ & $21.30 \%$ & 1.10 \\
\hline Wanted to fill time & $12.48 \%$ & $15.95 \%$ & 0.90 \\
\hline Wanted to help child with special problems & $63.95 \%$ & $68.65 \%$ & 0.69 \\
\hline Wanted to help community/society & $51.72 \%$ & $83.56 \%$ & $7.80 * * *$ \\
\hline Wanted to increase family income & $5.86 \%$ & $13.19 \%$ & $2.02 *$ \\
\hline Wanted to provide good home to child & $94.14 \%$ & $96.34 \%$ & 1.02 \\
\hline Wanted to provide love to a child & $95.07 \%$ & $96.17 \%$ & 0.45 \\
\hline Was a foster child myself & $2.07 \%$ & $3.81 \%$ & 0.82 \\
\hline Was abused/neglected myself & $7.07 \%$ & $14.27 \%$ & $1.49^{+}$ \\
\hline
\end{tabular}

Note: $t$ tests use jackknife standard errors to account for multistage cluster sample design; *** Two tailed $p<0.01 * * p<0.05 * p<0.1 ;+$ One-tailed $p<0.1$. 
There are eight motivations where there are statistically significant differences between the groups. A cursory glance at the table reveals that not all of the motivations appear to be altruistic. To fix ideas, the discussion groups the eight motivations where there were statistically significant differences according to their degree of altruism.

There are two motives that stand out as clearly non-altruistic. Notably, the motivations, child to help with business/chores, and wanted to increase family income were all chosen more frequently by persons with religious motivation. And these differences were statistically significant. This suggests that not all religiously motivated foster parents possess solely altruistic motivations for providing foster care. This is important, for it suggests that there may be a more concentrated core of persons that possess both religious motivation and mostly altruistic motives.

The second group of motivations where there are statistically significant differences is somewhat indeterminate in terms of being truly altruistic. Four of the motivations for fostering seem to fit in this "nebulous" category: wanted certain type of child, wanted to be loved by a child, had child who died, and was abused/neglected myself. For all of these motivations, the statistical evidence is weaker, as all only attain one-tailed significance at the 10 percent level.

Arguably wanted certain type of child could be altruistic (if a parents desired a special needs child) or it could be less so if the parent was unwilling to take children unless they had few special needs. While we cannot be sure exactly how altruistic this motivation is, the results show that religiously motivated foster parents are more likely to want a special type of child. Interestingly, religiously motivated foster parents are less likely to list wanted to be loved by a child as a reason for fostering. Certainly the rationale for why this is so calls for speculation, but perhaps religiously motivated families are less driven by loneliness as a reason for fostering. Moreover, while it would be difficult to make an unequivocal statement that the desire to be loved by a child is non-altruistic, it certainly is less altruistic than other possible motivations. Religiously motivated parents were also more likely to foster because they had a child who died or were abused or neglected myself. Again, these are not clearly altruistic or non-altruistic, but in both cases religiously motivated parents were more likely to choose these as reasons.

The two reasons for fostering where we see the most significant statistical difference, seem to also be those most clearly altruistic in nature. Just over $79 \%$ of religiously motivated foster parents chose the first motivation, to give a home to a child who would've been in an institution, which is $14 \%$ more than parents who were not religiously motivated. The second motivation, wanted to help community/society, also was chosen more frequently by the religiously motivated group, with $83.56 \%$ choosing this reason as opposed to only $51.72 \%$ of the non-religiously motivated group. The group differences on these last two items are the highest both in absolute magnitude, and in terms of statistical significance, lending support to the proposition that religiously motivated persons will possess altruistic motives for fostering in greater numbers.

Looking beyond simple exploratory analysis of all reasons for fostering, another approach sheds some additional light on the question of altruism. Among the 27 reasons for fostering there are several which seem clearly to be altruistic in nature. Specifically, Wanted to provide love to a child, Wanted to provide good home to a child, To give a home to a child who would've been in an institution, Wanted to help a child with special problems and Wanted to do something for the 
community/society all stand out as altruistic. A simple additive index of altruism can be constructed by adding each of these items into a single scale of altruism.

Before proceeding into analysis of the differences in the index, a natural question arises regarding the validity of combining these items into a single index; that is, do all of these reasons for fostering truly reflect a single dimension (i.e., altruism)? We can employ a principal components analysis to investigate this. If the individual items that comprise the scale are multidimensional, a principal components analysis would result in the scale items loading on more than one factor. On the other hand, if all items load on a single factor, we have reason to believe that the scale items are related to a single underlying factor. Table 2 presents the principal component analysis results. A common rule of thumb in principal components analysis is to only retain factors that have an Eigenvalue greater than or equal to one, and to discard factors that do not meet this threshold [27]; the actual statistical analysis resulted in only one factor with an Eigenvalue greater than one. This confirms that this subset of reasons for fostering is uni-dimensional. Moreover, each of the reasons for fostering in the index has a positive factor loading on this single dimension, showing that they are positively associated with altruism.

Table 2. Principal Components Analysis of Altruistic Reasons for Fostering.

\begin{tabular}{ll}
\hline Reason for Fostering & Factor Loading \\
\hline Wanted to provide love to a child & 0.688 \\
\hline Give home to child who would've been in institution & 0.657 \\
\hline Wanted to help child with special problems & 0.629 \\
\hline Wanted to help community/society & 0.508 \\
\hline Wanted to provide good home to child & 0.718 \\
\hline Eigenvalue & 2.074 \\
\hline Percentage of Variance Explained & 41.48 \\
\hline
\end{tabular}

Now that we have confirmation of the validity of the additive altruism index using these measures, we can proceed to analyzing how index scores differ by religious motivation. Table 3 compares the values of the additive altruism scale by religious motivation. There are definitely differences between the groups. A much larger relative proportions of non-religiously motivated persons fell on levels two and three of the scale. In contrast, a much larger relative proportion of religiously motivated persons are at levels four and five of the scale. A simple chi square test confirms the basic difference between the groups, yielding a design-adjusted test statistic of 4.23 , with a $p$ value of $0.01 .{ }^{1}$ Moreover, the mean score on the index for religiously motivated foster

1 Though the chi square test confirms a difference between groups, statistically it cannot evidence a clear direction of association. Other measures of association such as the Gamma statistic can show such directional association, but unfortunately, the survey data analysis module in STATA does not offer these other measures of association. A simple alternative is to employ ordered logit regression which is appropriate for an additive index. The independent variable is the presence of religious motivation for fostering, coded as a dummy variable equal to one if religious motivation is present. The coefficient on the religious variable is positive $(0.891)$ and statistically significant $(p=0.001)$, suggesting that religious motivation is positively associated with the altruism index. 
parents is larger (4.24) as compared to parents without religious motivation (3.69). And the difference of means is statistically significant $(p=0.000)$.

Table 3. Altruism Scale by Religious Motivation.

\begin{tabular}{ccc}
\hline Altruism Score & Not Religiously Motivated & Religiously Motivated \\
\hline 0 & $2.21 \%$ & $0.0 \%$ \\
\hline 1 & $3.28 \%$ & $4.48 \%$ \\
\hline 2 & $12.06 \%$ & $1.14 \%$ \\
\hline 3 & $19.39 \%$ & $10.86 \%$ \\
\hline 4 & $31.56 \%$ & $32.7 \%$ \\
\hline 5 & $31.49 \%$ & $50.82 \%$ \\
\hline Mean Score & 3.69 & 4.24 \\
\hline
\end{tabular}

Note: Each cell contains weighted cell counts, and within-column percentages in parenthesis below; Design-based chi square $=4.23, p=0.01$.

In sum, the empirical investigation in this section demonstrates that there are differences in motivation between religiously motivated foster parents and their non-religiously motivated counterparts. Surprisingly, religiously motivated parents were more likely to choose two clear non-altruistic motivations (child to help with business/chores, and wanted to increase family income). However, the largest and most significant differences in motivation were found in two fairly non-ambiguous altruistic motives: to give a home to a child who would've been in an institution and wanted to help community/society. In both cases, religiously motivate foster parents were more likely to choose these as reasons for fostering. Moreover, religiously motivated persons had higher scores on the altruism index confirming that religious motivation is positively associated with altruism Taken together, these findings indicate that religiously motivated foster parents are, on average, more likely to possess altruistic motives for fostering. However, this comes with a caveat because there were some religiously motivated parents that had relatively higher incidences of non-altruistic motives as well. This suggests that religious motivation is not always coincident with altruism, a finding which turns out to be important when we employ religious motivation for fostering as an independent variable in empirical models.

\section{Religious Motivation, Altruism and the Foster Home Outcomes}

Knowledge of the association between religious beliefs and other altruistic motivations for fostering is useful, but do religious motivations for fostering translate into actual differences in substantive measures of foster parent utilization and longevity? We now turn to an examination of the relationship between religious motivation, altruism and some measures of foster home utilization and continuation.

Before going into the results themselves, it is necessary to explain how the effects of religious beliefs are modeled empirically here. In running preliminary exploratory models, it was somewhat of a surprise to find that religious beliefs alone almost never made a difference. This confirms the findings of earlier work using the NSCFFP, which failed to find any significant relationships between religious motivation for fostering and a variety of foster parent capacity outcomes [20]. 
Thinking back to the altruism results of the previous section, it became clear why religious motivation alone did not produce any significant result: not all religiously motivated people are altruistic, even though they are, on average, more altruistic than persons that are not religiously motivated.

Allport's classic work on the psychology of religion speaks of "mature religion" [28], a concept that has been further distilled and is commonly called intrinsic religiosity [29]. Intrinsic religious motivation is seen as more of an end in itself, reflective of a faith that permeates life and is not instrumental. In contrast, extrinsic religiosity has been described as one that, "serves an instrumental purpose, providing comfort or social reward, and is compartmentalized in the life of an individual, used as a means toward other ends" ([30], p. 430). ${ }^{2}$ Research shows that extrinsic versus intrinsic religious motivations matter for attitudes and behavior. In particular, those that possess an intrinsic religiosity have been shown to have a higher level of religious commitment and to have less prejudice. Scholars have also shown that people with extrinsic religious motivation are more prejudiced and are not altruistic [29].

The concept of intrinsic versus extrinsic religiosity provides a very useful framework to guide the empirical work in this study. That research shows that not all people with religious belief are altruistic; especially those that possess an intense extrinsic religiosity. This is consistent with the earlier section of this paper, which showed that some people with religious motivation for fostering had some decidedly non-altruistic reasons for so doing.

The concept of intrinsic religiosity can be aptly characterized as a religiosity that is coincident with less selfish motivations. Using the NSCFFP data, what variables could be used to best identify the group that possesses a more altruistic religious motivation? Most of the studies on intrinsic/extrinsic religiosity employ an array of attitudinal questions, but the NSCFFP survey did not focus on religious motivation in detail, it simply allowed respondents to check off "religious beliefs" as one of many possible motivations for fostering. One approach for identifying the subgroup that possesses more of an altruistic religious motivation would be to construct some sort of measure that more clearly demarcates them from the larger group of persons who may be religiously motivated, but are not necessarily altruistic. This is done by means of an interaction term of religious motivation and altruism.

The empirical setup for modeling the interaction of religious motivation and altruism requires a bit of explication. To begin, define three dummy variables: the first equal to one if the person fostered because of religious beliefs; the second equal to one if the respondent had a "perfect" altruism score (i.e., selected all five altruistic reasons for fostering); and the third, a dummy variable that is the product of the other two. In other words, the third dummy variable is equal to one if the respondent had religious reasons for fostering and a perfect altruism score. Referring back to the altruism index in Table 2, this would be all of the cases with religious motivation and an altruism score equal to 5 in the bottom right hand cell.

2 This paper does not even attempt to capture the rich literature on intrinsic and extrinsic motivation. And it should be readily acknowledged the intrinsic-extrinsic conceptualization has been the subject of numerous methodological discussions since Allport's original work was introduced (See [29] for an excellent synopsis). Rather, the intrinsic-extrinsic framework is introduced here as a means for explaining the varied underlying motivations for religiosity and their attendant outcomes as manifest in actual behavior. 
The choice of the altruism score equal to 5 is not an arbitrary one. The results from Table 3 show that the average score for the religiously motivated group was 4.24 . If it really does take an especially high level of commitment to be a successful foster parent, then it makes sense that we would want to isolate the marginal effects for the group with the highest level of commitment. That is, we would want to identify people with an above average altruism score, which in this case would be a perfect score of 5 (i.e., $5>4.25$ ). Moreover, Table 2 shows that over 50 percent of the religiously motivated group had an altruism score of five, so this subgroup is not a minority of religiously motivated foster parents.

Use of three separate dummy variables facilitates a nuanced understanding as to how different sources of motivation for fostering operate. In the equation below we can see this more clearly. The coefficient on the dummy variable for religious motivation $(\alpha)$ measures the marginal effect of religious beliefs and the coefficient on altruism $(\beta)$ measures the marginal effect of altruism. Finally, the coefficient on the interaction term $(\delta)$ measures the marginal effect of being both religious and altruistic. For our purposes, this is the most interesting parameter because it will indicate the effect for the smaller group of foster parents who are religiously motivated and highly altruistic.

$$
\text { Total Effect }(T E)=\alpha(\text { Religious })+\beta(\text { Altruism })+\delta(\text { Religious } * \text { Altruism })
$$

Consider some outcome measure, say, the number of foster children in the home. From an empirical standpoint, if it is true that religious altruists will have "better" foster parenting outcomes, we would expect $\delta$ to be positive. Furthermore, the total effect (which is the sum of the marginal effects, $(\alpha+\beta+\delta)$ should also be positive, indicating a difference between those that are religious altruists and those that are neither religiously motivated, nor as altruistic.

The empirical analyses report the baseline results, using just the dummy variables described above alongside results that use a more extensive set of control variables used in other applied work [17,31-34]. The results are reported in this way so that we may see how robust the underlying relationships are with the central variables of interest (i.e., religious motivation, altruism and their interaction). The control variables include the year the family began to foster, the mother's age and age squared (to account for eventual dropping out due to aging) ${ }^{3}$, dummy variables for mother's race, family income (modeled as a vector of dummy variables) ${ }^{4}$, marital status, urbanicity and the generosity of the state's foster payment levels (This last variable mirrors the three payment strata of high, medium and low used in the initial sampling design; low payment states are used as the excluded base case).

Before proceeding to the empirical results, there is one further matter that requires an explanation. As already noted in the previous discussion of the NSCFFP data, the design employed a complex, multi-stage cluster sample. When analyzing such data, traditional statistical methods break

3 Father's age could also be used as in [17]. Use of father's age as a regressor comes at a price because it significantly reduce the effective sample size by 170 unweighted observations. Further, because single female headed households would have missing values, using father's age eliminates them from the sample as well. In auxiliary regressions where I used father's age, the coefficients were largely analogous.

4 The NSCFFP does not have continuous data for income, but reports income as an ordinal variable across several income intervals. 
down, because they do not take weighting, design and clustering effects into account. The statistical software (STATA) has a series of commands that have been modified especially for complex survey data. Because of the uniqueness of complex survey data, traditional measures of goodness of fit employed with nonlinear models, such as the pseudo-r square, cannot be calculated [35]. However, a modified version of the F statistic can still be computed, providing a test of the null hypothesis that all coefficients in the mode are jointly zero. So, while no pseudo r-squared statistics can be computed (and hence be reported) the modified $\mathrm{F}$ statistic is provided in lieu of more traditional goodness of fit measures.

\subsection{Empirical Results for Utilization Measures}

The first outcomes are basic measures of foster home utilization: the probability that a foster child is currently placed in the home and the total number of foster children currently placed in the home. Given that all parents in this sample are licensed foster parents, they are all potential foster homes, but not all homes had a foster child residing in them at the time of the interview. To the extent that there is normally an imbalance of children needing foster homes to available homes, this is a crucial utilization measure. If motivations do have an effect, then religious altruists might be more likely to be actively fostering by having a child in their home.

Table 4 compares the baseline results and those with the control variables for the first utilization measure, the probability that a foster child is currently residing in the home. Both of these models were estimated using logistic regression. The F statistic measuring global goodness of fit is only significant for the full model with controls though many of the individual coefficients are statistically significant.

Table 4. Logistic Regression Results for Presence of Foster Child in Home.

\begin{tabular}{lll}
\hline $\begin{array}{l}\text { Dependent Variable: Probability that a Foster } \\
\text { Child is Currently in the Home }\end{array}$ & Baseline & $\begin{array}{l}\text { Controls } \\
\text { Added }\end{array}$ \\
\hline Marginal Effect of Religious Motivation $(\alpha)$ & $-0.785^{+}$ & $-0.808^{+}$ \\
\cline { 2 - 3 }$(0.509)$ & $(0.545)$ \\
\hline Marginal Effect of Altruism $(\beta)$ & -0.279 & -0.238 \\
\hline & $(0.313)$ & $(0.352)$ \\
\hline Marginal Combined Effect of Religious & $1.72 * *$ & $1.73 *$ \\
\cline { 2 - 3 } Motivation and Altruism $(\delta)$ & $(0.793)$ & $(0.829)$ \\
\hline Control Variables & No & Yes \\
\hline N & 729 & 729 \\
\hline F Statistic & 1.58 & $19.35^{* *}$ \\
\hline Linear Combination of Religious Motivation and & $0.657^{+}$ & $0.682 *$ \\
\cline { 2 - 3 } Altruism $(\alpha+\beta+\delta)$ & $(0.383)$ & $(0.365)$ \\
\hline
\end{tabular}

Note: Table reports coefficients with jackknife standard errors in parenthesis below; *** Two tailed $p<0.01 * * p<0.05 * p<0.1 ;+$ One-tailed $p<0.1$. 
In both models, the marginal effect of religious motivation is negative, as is the marginal effect for altruism. However, the marginal effect of being both religious and altruistic has a statistically significant and positive association with the probability that a foster child is currently in the home ( $\delta$ is just over 1.7 in both models). To find the total effect for religious altruists, the individual coefficients must be summed. This linear combination of coefficients is reported at the bottom of the table. The linear combination is positive in each case, showing that religious altruists have a higher probability of having a foster child in their homes Using the estimate for the full model with controls of 0.682 , this translates into an odds ratio of about 1.98 to 1 (i.e., $\mathrm{e}^{0.682}=1.98$ ), meaning that the odds for religious altruists having a child in their home are nearly twice those for the base case (non-religiously motivated persons without a perfect altruism score). These results suggest that religious altruists are allowing their homes to be occupied by foster children on a more frequent basis. Of course, this result may also be picking up the effects social worker selectivity; that is, some social workers may attempt to place foster children in the homes of religious altruists first before trying other homes.

The second measure of utilization is the number of foster children currently in the home. The results for this measure are contained in Table 5. These were estimated using negative binomial regression, which is often used with count data when there are no negative values of the dependent variable. ${ }^{5}$

Table 5. Negative Binomial Regression Results for Number of Foster Children in Home.

\begin{tabular}{lll}
\hline $\begin{array}{l}\text { Dependent Variable: Number of Foster } \\
\text { Children }\end{array}$ & Baseline & Controls Added \\
\hline Marginal Effect of Religious Motivation $(\alpha)$ & $-0.640 * *$ & $-0.656 * *$ \\
\cline { 2 - 3 } & $(0.270)$ & $(0.273)$ \\
\hline Marginal Effect of Altruism $(\beta)$ & -0.126 & -0.108 \\
\hline & $(0.138)$ & $(0.139)$ \\
\hline Marginal Combined Effect of Religious & $1.09 * *$ & $1.08 * *$ \\
\cline { 2 - 3 } Motivation and Altruism $(\delta)$ & $(0.388)$ & $(0.399)$ \\
\hline Control Variables & No & Yes \\
\hline $\mathrm{N}$ & 729 & 729 \\
\hline F Statistic & $3.87 * *$ & $5.87 *$ \\
\hline Linear Combination of Religious Motivation & $0.32 * *$ & $0.317 * *$ \\
\cline { 2 - 3 } and Altruism $(\alpha+\beta+\delta)$ & $(0.144)$ & $(0.134)$ \\
\hline
\end{tabular}

Note: Table reports coefficients with jackknife standard errors in parenthesis below; *** Two tailed $p<0.01 * * p<0.05 * p<0.1 ;+$ One-tailed $p<0.1$.

The results closely resemble those in Table 4: the individual effects of religious reasons for fostering and altruism are negative, but the marginal effect of the interactive term $(\delta)$ is positive and statistically significant, again underlining the importance of the two working in tandem. The overall

5 Negative binomial models are preferred over Poisson models when over-dispersion is present in the data. The estimates of the dispersion parameter in the negative binomial regression evidenced the presence of slight over-dispersion. Accordingly, negative binomial regression was used. (The dispersion parameter, ln alpha, was equal to -1.47 in the full model, corresponding to a slight dispersion of 0.23 ). 
effect for religious altruists (as computed with the linear combination of coefficients, $(\alpha+\beta+\delta)$ is again positive and statistically significant; the baseline model result is 0.32 and the full model returns a value of 0.317 . In a negative binomial regression the coefficients can be interpreted as the proportional change in the count for a change in the regressor [36]. This can be made even more interpretable by multiplying the coefficient by 100 to get the percentage change. Here the interpretation is that religious altruists are expected to have about $32 \%$ (i.e., $0.317 * 100$ ) more children in their homes.

In sum, the results for the first set of models show that religious altruists are more likely to have at least one foster child residing in their homes. They also have a greater number of foster children. This certainly has practical implications given the shortage of family foster homes. It appears that households with religious and altruistic motivations maintain a higher level of utilization.

\subsection{Empirical Results for Intent to Continue Fostering}

If it is true that religious altruism leads to greater fostering utilization, it also stands to reasons that religious altruists would be more likely to continue fostering. The NSCFFP asked all of the current foster parents the question, "Thinking ahead, over the next three years, do you intend to continue as a foster parent?" The response was coded as a dummy variable, equal to one if the answer was yes and zero if no. Therefore a positive regression coefficient would indicate an increase in the probability of continuing as a foster parent and a negative coefficient would indicate an increase in the probability of quitting.

Table 6 reports logistic regression results where the dependent variable is the respondent's stated intent to continue fostering in the next three years. The sample size is slightly smaller (659 versus 729) for these regressions because of missing data on the dependent variable. The F statistics for both regressions are very small, suggesting an overall poor fit.

Table 6. Logistic Regression Results for Intent to Continue Fostering.

\begin{tabular}{lll}
\hline $\begin{array}{l}\text { Dependent Variable: Probability that Foster } \\
\text { Parent Intends to Continue Fostering }\end{array}$ & Baseline & Controls Added \\
\hline Marginal Effect of Religious Motivation $(\alpha)$ & -0.039 & 0.076 \\
\cline { 2 - 3 } & $(0.436)$ & $(0.459)$ \\
\hline Marginal Effect of Altruism $(\beta)$ & 0.153 & 0.152 \\
\hline & $(0.357)$ & $(0.33)$ \\
\hline Marginal Combined Effect of Religious & 0.045 & -0.126 \\
\cline { 2 - 3 } Motivation and Altruism $(\delta)$ & $(0.942)$ & $(0.893)$ \\
\hline Control Variables & No & Yes \\
\hline N & 659 & 659 \\
\hline F Statistic & 0.07 & 0.51 \\
\hline Total Effect of Religious Motivation and & 0.159 & 0.102 \\
\cline { 2 - 3 } Altruism $(\alpha+\beta+\delta)$ & $(0.76)$ & $(0.763)$ \\
\hline
\end{tabular}

Note: Table reports coefficients with jackknife standard errors in parenthesis below; *** Two tailed $p<0.01 * * p<0.05 * p<0.1 ;+$ One-tailed $p<0.1$. 
It appears that religious motivation and/or altruism make little difference on intent to continue fostering. There is no statistically significant effect with any of the marginal components or even their linear combination. Of course, intent is not same as an actual decision to quit, so these findings are not definitive. But they certainly show that religious altruists did not have discernibly more expressed motivation to continue as foster parents.

To summarize, the results from the empirical analysis are somewhat mixed. They indicate that homes of religious altruists are more likely to be utilized at a higher rate among all eligible foster parents. Religious altruists are more likely to have a foster child in their home and to have a larger number of foster children. But there was no statistically significant difference between religious altruists and others in terms of their expressed intent to continue fostering, a finding which fails to confirm the hypothesis that religiously motivated foster parents would have greater longevity as caregivers.

\section{Conclusions}

This paper has examined the empirical linkages between religious motivation, altruism and fostering. In a time where faith-based collaboration in child welfare systems is on the rise, understanding how and why religious motivations translate into substantive outcomes for foster homes is increasingly important for practitioners in child welfare. The research findings do have some important implications for child welfare practice.

First, though it is clear that religiously motivated parents are more likely to be altruistic, not all parents in this group are altruistic. This finding accords with the literature on extrinsic versus intrinsic religious motivation. It also implies that not all faith communities would be ready to engage in long-term child welfare partnerships. Accordingly, care must be taken when selecting faith communities to serve as collaborative partners and in the selection of individual foster caregivers. Perhaps appropriate pilot testing or other incremental steps could be taken by officials on the government side to assure that particular faith communities are indeed ready to serve as faithful long-term partners. In addition, social workers will need to pay close attention to prospective foster parents' motivations for fostering and not merely assume that because religious motivation is present that this equates to altruism.

Second, the association between religious altruism and foster home utilization is a very important one for social work practice. In a time of dwindling resources and greater need for foster families, finding parents in this religious altruist group could be a real boost to the operating capacity of the foster care system.

Third, the lack of association found between religious altruism and intent to continue fostering suggests that motivation by itself may not be sufficient to uphold foster parents over the long haul. This obviates the need for study of other auxiliary systems of support and nurture for foster parents to keep them motivated to serve as caregivers. It could be that some faith communities do, in fact, provide some of those needed supports. More study of the other ways in which faith communities work to support and aid foster parents could yield some interesting insights here.

There are also many questions that this research leaves unanswered and limitations which must be acknowledged. First, what does a religious motivation for fostering really amount to? The 
NSCFFP only provides the broadest of descriptions. "Religious beliefs" is a fairly sweeping and ambiguous umbrella term that leaves much to be explored-perhaps some religious motivations are different from others. Also, though it is certainly reasonable to propose that we would be more likely to find religiously motivated people in places of worship, we cannot infer much about the types of congregations in which religiously motivated foster parents are found. Are there certain religions or denominations where it is more likely that this group would be found? These questions merit further data collection and investigation.

Second, the NSCFFP represents the only nationally representative foster parent data that we have available, and while the data are high in quality they are more than 20 years old. This calls for more data collection by the U.S. Department of Health and Human Services (or others). The findings might change with newer data. The findings here, though significant, undoubtedly will need further validation by scholars elsewhere using different data.

Third, the measures of foster home utilization employed in this research are, at best, an imperfect measure of foster home quality. It could be argued that just because some foster parents are more likely to take in one or more foster children, their motive are not necessarily altruistic. Social worker selectivity might also be at work here: perhaps they send children to certain households because they are less of a hassle for them, for example. Moreover having multiple foster children in a home might arguably decrease the quality of care available to each child (though the care received still might be better than the alternative). And so, while the data do establish a relationship between religious altruism and utilization, the ultimate question of the linkage between religious motivation and foster home quality remains unanswered. ${ }^{6}$

This initial empirical look at faith, altruism and fostering reveals many other intriguing questions in need of further research. For example, how do outcomes with recent faith-based initiatives in the area of child welfare square with the more general empirical associations found here? This calls for in-depth fieldwork on a more national scale. What is motivating local faith congregation members to provide foster care and/or adoption? Are their motives altruistic or not? Are these programs seeing success in terms of greater foster parent capacity and longevity? To conclude, this paper points to some interesting connections between religious motivation, altruism and fostering. Using a nationally representative sample of foster parents, this research provides some initial evidence that foster homes with parents that possess religious and altruistic motives provide a higher level of utilization as caregivers. As interest in foster care and adoption continues to mount from faith-based circles, the findings here suggest that such efforts may bear some fruit. These results point to the promise of further investigation into specific faith-based child welfare initiatives around the country in an attempt to understand if they do offer some unique and innovative potential for the foster care system.

\section{Conflicts of Interest}

The authors declare no conflict of interest.

$6 \quad$ I am indebted to an anonymous reviewer for providing this insight. 


\section{References}

1. U.S. Department of Health and Human Services. The AFCARS Report: Preliminary 2012 Estimates. Available online http://www.acf.hhs.gov/sites/default/files/cb/afcarsreport20.pdf. (accessed on 6 June 2014).

2. Kathy Barbell, and Madelyn Freundlich. Foster Care Today. Washington: Casey Family Programs, 2001.

3. Office of Inspector General. Retaining Foster Parents. Washington: U.S. Department of Health and Human Services, 2002.

4. Office of Inspector General. Recruiting Foster Parents. Washington: U.S. Department of Health and Human Services, 2002.

5. General Accounting Office. Foster Parents: Recruiting and Preservice Training Needed. Washington: United States General Accounting Office, 1989.

6. Kathryn Rhodes, John Orme, and Cheryl Buehler. "A comparison of foster parents who quit, consider quitting and plan to continue fostering." The Social Services Review 75 (2001): 84-115.

7. John Orme, Cheryl Buehler, Michael McSurdy, Kathryn Rhodes, Mary Ellen Cox, and David Patterson. "Parental and Familial Characteristics of Family Foster Care Applicants." Children and Youth Services Review 26 (2004): 307-29.

8. Kathy Barbell, and Lisa Sheikh. A Community Outreach Handbook for Recruiting Foster Parents and Volunteers. Washington: Child Welfare League of America Press, 2000.

9. Casey Family Programs. Recruitment and Retention of Foster Families: Promising Practices and Lessons Learned. Seattle: Casey Family Programs, 2005.

10. Marcia Cipriani, Kris Henneman, and Judith McKenzie. Finding Common Ground: A Guide for Child. Welfare Agencies Working With Communities of Faith. Baltimore: The Collaboration to Adopt US Kids, 2004.

11. Eileen Pasztor, Dori Shannon, and Patricia Buck. A Community Approach to Foster Parent Recruitment and Retention: A Strategies Codebook. Atlanta: Child Welfare Institute, 1989.

12. Eileen Pasztor, and Susan Wynne. Foster Parent Retention and Recruitment: The State Of The Art in Practice and Policy. Washington: Child Welfare League of America, 1995.

13. Urban Institute Child Welfare Research Program. Foster Care Adoption in the United States: An. Analysis of Interest in Adoption and a Review of State Recruitment Strategies. Washington: The Urban Institute, 2005.

14. John Orr, Grace Roberts Dyrness, and Peter Spoto. Faith-Based Adoptive/Foster Services: Faith Communities' Roles in Child Welfare. Los Angeles: Center for Religion and Civic Culture, University of Southern California, 2004.

15. Cheryl Buehler, Kathryn Rhodes, John Orme, and Gary Cuddeback. "The Potential for Successful Family Foster Care: Conceptualizing Competency Domains for Foster Parents." Child Welfare 85 (2006): 523-56.

16. Isabel Dando, and Brian Minty. "What Makes Good Foster Parents?" British Journal of Social Work 17 (1987): 383-400.

17. Ramona Denby, Nolan Rindfleisch, and Gerald Bean. "Predictors of Foster Parents' Satisfaction and Intent to Continue to Foster." Child Abuse and Neglect 23 (1999): 287-303. 
18. J. Kraus "Selective Campaigning for Foster Homes: An Empirical View." Australian Social Work 28 (1975): 59-64.

19. Susan Rodger, Anne Cummings, and Alan Leschied. "Who is Caring for Our Most Vulnerable Children? The Motivation to Foster in Child Welfare." Child Abuse and Neglect 30 (2006): 1129-42.

20. Kathryn Rhodes, Mary Ellen Cox, John Orme, and Tanya Coakley. "Foster Parents' Reasons for Fostering and Foster Family Utilization." Journal of Sociology and Social Welfare 33 (2006): 105-26.

21. Judy Sebba. Why Do People Become Foster Carers: An International Literature Review on the Motivation to Foster. Oxford: Rees Centre, University of Oxford, 2012.

22. Jennifer Geiger, Megan J. Hayes, and Cynthia A. Lietz. "Should I Stay or Should I Go? A Mixed Methods Study Examining the Factors Influencing Foster Parents' Decisions to Continue or Discontinue Providing Foster Care." Children and Youth Services Review 35 (2013): 1356-65.

23. Skrallan De Maeyer, Johan Vanderfaeillie, Femke Vanschoonlandt, Marijke Robberechts, and Frank Van Holen. "Motivation for Foster Care." Children and Youth Services Review 36 (2014): 143-49.

24. Matthew Colton, Susan Roberts, and Margaret Williams. "The Recruitment and Retention of Family Foster-Carers: An International and Cross-Cultural Analysis.” British Journal of Social Work 38 (2008): 865-84.

25. Angela Baum, Sedahlia Crase, and Kristen Crase. "Influences on the Decision to Become or not Become a Foster Parent." Families in Society 82 (2001): 202-13.

26. National Data Archive on Child Abuse and Neglect. National Survey of Current and Former Foster Parents. Ithaca: Cornell University, 2000.

27. Henry F. Kaiser "The Application of Electronic Computers to Factor Analysis." Educational and Psychological Measurement 20 (1960): 141-51.

28. Gordon Allport. The Individual and His Religion: A Psychological Interpretation. New York: Macmillan, 1950.

29. Michael J. Donahue. "Intrinsic and Extrinsic Religiousness: Review and Meta-Analysis." Journal of Personality and Social Psychology 48 (1985): 400-19.

30. A. Michael MacLean, Lawrence Walker, and M. Kyle Matsuba. "Transcendence and the Moral Self: Identity Integration, Religion and Moral Life.” Journal for the Scientific Study of Religion 43 (2004): 429-37.

31. Mary Ellen Cox, Cheryl Buehler, and John Orme. "Recruitment and Family Foster Service." Journal of Sociology and Social Welfare 29 (2002): 151-77.

32. Kathryn Rhodes, John Orme, Mary Ellen Cox, and Cheryl Buehler. "Foster Family Resources, Psychosocial Functioning, and Retention.” Social Work Research 27 (2003): 135-50.

33. Nolan Rindfleisch, Gerald Bean, and Ramona Denby. "Why Foster Parents Continue and Cease to Foster." Journal of Sociology and Social Welfare 25 (1998): 5-24.

34. Julian Simon. "The Effect of Foster-Care Payment Levels on the Number of Foster Children Given Homes." Social Service Review 49 (1975): 405-11.

35. Kellie Archer, and Stanley Lemeshow. "Goodness-of-Fit Test for a Logistic Regression Model Fitted Using Survey Sample Data.” The Stata Journal 6 (2006): 97-105. 
36. Jeffery $\mathrm{T}$ Walker, and Sean Maddan. Statistics in Criminology and Criminal Justice: Analysis and Interpretation, 2nd ed. Sudbury: Jones and Bartlett Publishers, 2005.

(C) 2014 by the author; licensee MDPI, Basel, Switzerland. This article is an open access article distributed under the terms and conditions of the Creative Commons Attribution license (http://creativecommons.org/licenses/by/3.0/). 